\title{
Development and Validation of a RP-HPLC Method for the Determination of Ellagic Acid in Terminalia bellirica Extract and Single Herb Capsule of Terminalia bellirica
}

\author{
Purnima J Ganjage ${ }^{1}$, Amit S Tapkir ${ }^{1}$, Sanjay U Nipanikar², Dheeraj Hanumansingh Nagore ${ }^{2}$, Prachi K \\ Pawar $^{2}$, \\ Monali L Phophase ${ }^{2}$
}

${ }^{1}$ Pharmaceutical Chemistry Department, P. E. Society Modern College of Pharmacy, Nigdi, Pune, Maharashtra, INDIA. ${ }^{2}$ Ari Healthcare Private Limited, R and D Centre, Unit No. 401, International Biotech Park, BTS-2 Building, Chrysalis Enclave, $4^{\text {th }}$ Floor, Plot No - 2A, MIDC Phase II, Hinjewadi, Pune, Maharashtra, INDIA.

\begin{abstract}
Objective: The present work describes development and validation of a simple, specific, sensitive, precise, reproducible and robust high performance liquid chromatographic method of analysis of Ellagic acid, as in Terminalia bellirica extract and from capsule formulation. A validated rapid HPLC-PDA method was developed for identification and quantification of Ellagic acid (EA) in the extracts prepared from the fruits of Terminalia bellirica available in India. Methodology: The separation was achieved on a Waters HPLC system coupled with a PDA detector. The separation was achieved by using mobile phase in composition of $\mathrm{n}$-Hexane sulfonic acid $(20 \mathrm{mM}$ ) and $100 \%$ Methanol (Gradient programme) at flow rate of $0.7 \mathrm{ml} / \mathrm{min}$ was used. Results: The retention time for Ellagic acid was found to be $21 \mathrm{~min}$. The system suitability parameters were calculated and were found to be within limits. Linear relationship was obtained between response and amount of drug with high correlation coefficient (R2) in the range 250-750 ppm for Ellagic acid $(\mathrm{R} 2=0.9998)$. The results of formulation analysis were validated as per International Council of Harmonization $(\mathrm{ICH})$ guidelines indicating high degree of accuracy. Conclusion: The \% R.S.D. value which is less than to 2 for robustness study suggests that the developed HPLC methods are unaffected by small changes in process parameters.
\end{abstract}

Key words: Terminalia bellirica, Ellagic acid, RP-HPLC, Validation, ICH Guidelines.

\section{INTRODUCTION}

Natural products have been a highly productive source of leadbioactive molecules. ${ }^{1,2}$ Fruits and barks of Terminalia belliricaspecies have been used since the Vedic period for the treatment of various diseases. ${ }^{3}$ Many preparationsfrom Terminalia bellirica species are used in traditional medicineas a cardiac tonic and diuretic. ${ }^{4}$ Terminalia bellirica is a large genus ofdeciduous trees of the flowering plant family Combretaceae comprising of 250 species distributed in the tropical regions of the world. ${ }^{5}$ About 16 species occur in India. The medicinal properties of Terminalia bellirica species depend on the species and itsorgan; however, the presence of tannins in the fruits and barks is almost characteristics of this genus. Terminalia bellirica species representsa rich source of phenolic acids, tannins, cyclic triterpenoids and flavonoids. Their exact chemical classes and levels vary in different Terminalia species. ${ }^{6}$ T. bellirica grows wild up to $1,000 \mathrm{~m}$, allover India except dry and marshy areas. The fruits of T. bellirica contain b-sitosterol,
Submission Date: 02-10-2017; Revision Date: 08-11-2017; Accepted Date: 17-05-2018

DOI: 10.5530/ijper.52.4s.76 Correspondence: Dr. Dheeraj Hanumansingh Nagore,

Senior Manager, Analytical Department, Ari Healthcare Private Limited, R and D Centre, Unit No. 401. International Biotech Park, BTS-2 Building, Chrysalis Enclave, 4th Floor, Plot No - 2A, MIDC Phase II, Hinjewadi, Pune - 411057, Maharashtra, INDIA. Phone: +91-8550993932 (M) E-mail: dheeraj.nagore@ arihealthcare.in

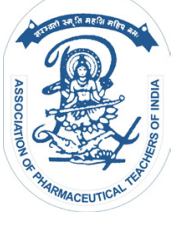

www.ijper.org 
gallic acid, ethyl gallate, chebulagicacid, mannitol, galactose, fructose and rhamnose. ${ }^{7}$ Fruits of T. bellirica exhibited hypotensive, purgative and cholerecticactivities. In combination with extract of Emblica officinal is it had protective effect in the experimental rats againstmyocardial necrosis. The bark may be used as an astringent fordressing wounds and sore throat. ${ }^{8,9}$

EA (Figure 1) is the major tannin-related constituents of Terminalia species present in about two-third proportions..$^{10} \mathrm{EA}$ is a potent antioxidant marketed as a nutritional supplement. ${ }^{11}$ It is dimeric derivative of gallic acid. ${ }^{12}$ It is 2,3,7,8-tetrahydroxy-benzopyrano5,10-dione.Its molecular weight is $302.19 \mathrm{~g} / \mathrm{mol}$ and the empirical formula is $\mathrm{C}_{14} \mathrm{H}_{6} \mathrm{O}_{8}$. EA, a dilactone of hexahydroxydiphenic acid, is found in raspberries, strawberries, cranberries, walnuts, pecans and other plant foods. ${ }^{13}$ EA has aroused great interest owing to its antioxidant, anti-inflammatory, and anti-neoplastic properties. ${ }^{14}$ EA is a highly thermodynamically stable molecule (Figure 1), with four rings representing the lipophilic domain and four phenolic and two lactone groups (which can act as hydrogen bond donor and acceptor, respectively) representing the hydrophilic part. Keeping in view of the above points in consideration, a rapid and simple HPLC method was developed for the identification and quantification of EA.

The aim of present work is to develop an accurate, specific, and reproducible HPLC method for determination of EA in Terminalia bellirica extracts and formulation respectively.

However, one of the impediments in the acceptance of the Ayurvedic or Herbal formulations is the lack of standard quality control profiles. The quality control of herbal medicine that is, the profile of the constituents in the final product has implications in efficacy and safety. ${ }^{15}$ Due to the complex nature and inherent variability of the chemical constituents of the plant based drugs, it is difficult to establish quality control parameters and modern analytical techniques like HPLC is expected to help in circumventing this problem. Hence, in the present paper we report the development of an optimized, validated and simple HPLC method for the estimation of EAfrom Terminalia bellirica and capsule formulation respectively.

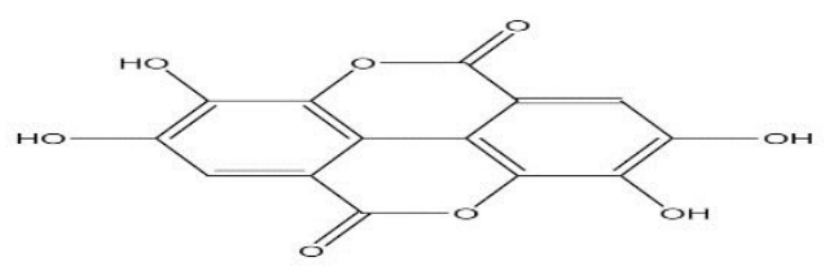

Figure 1: Structure of Ellagic acid.

\section{MATERIALS AND METHODS}

\section{Instruments}

HPLC instrument (waters 2998) PDA Detector Liquid chromatography with (Software "Empower"). It consists of Column Inertsil ODS $5 \mu$ (4.6 X $250 \mathrm{~mm}$ ).

Ultrasonicator water bath (LabtexInstruments) and Sartorious sensitive balance model SBT-224SCW were used. Merck Millipore Direct $\mathrm{Q}_{3}$ WaterPurification System was used to obtain Type I water.

\section{Plant Material Extracts}

The plant material extract of Terminalia bellirica is used for analysis is supplied by Kisalaya Herbals of batch number $(\mathrm{KBH} / 804)$ and the fruits part is used which is a hydroalcholic extract.

\section{Chemicals and Reagents}

Ellagic acid: It was kindly supplied byYucca Enterprises Pvt. Ltd. (Mumbai), its potency was foundto be $98 \%$ according to the reported method.

All chemicals used throughout the work were of analytical grade and solvents for HPLC were of HPLC grade. These included Methanol, n-hexane-Sulfonic acid and Water (Merck specialities Pvt. Ltd).

\section{Standard and test solutions}

\section{Preparation of the standard solution}

$10 \mathrm{mg}$ of EA was accurately weighed and transferred into $10 \mathrm{~mL}$ of volumetric flask. Add about $5 \mathrm{~mL}$ of diluent methanol and sonicate in ultrasonic water bath for $30 \mathrm{~min}$. Cool the solution and make up the volume with methanol to obtain stock solution of $1000 \mathrm{ppm}$. Use the resulting solution as standard solution.

\section{Preparation of the test solution for extract}

$50 \mathrm{mg}$ of Terminalia bellirica extract was weighed and transferred into a $20 \mathrm{~mL}$ of volumetric flask. Add about $15 \mathrm{~mL}$ of diluent methanol and then sonicate in ultrasonic water bath for $30 \mathrm{~min}$. Cool the solution and make up the volume with diluent methanol. Then filter through $0.45 \mu$ syringe filter. Use resulting solution as test solution.

\section{Preparation of test solution forBaheda SH capsule formulation}

$250 \mathrm{mg}$ of Baheda SH Capsule powder was weighed and transferred into a $20 \mathrm{~mL}$ volumetric flask. To this $15 \mathrm{~mL}$ of diluent methanol was added, sonicatedin ultrasonic water bath for $30 \mathrm{~min}$. Cool the solution and make up the volume with diluent methanol. Then filter through $0.45 \mu$ syringe filter. Use resulting solution as test solution. 


\section{Chromatographic conditions}

The method was carried out at ambient temperature on Inertsil ODS $5 \mu(4.6$ X $250 \mathrm{~mm})$ column. The mobile phase consisted of $\mathrm{n}$-hexane-sulfonic acidhaving $\mathrm{pH}=2.5 \pm 0.1$ adjusted withorthophosphoric acid and $100 \%$ Methanol (70:30, v/v). The mobile phase was filteredusing $0.45 \mathrm{~mm}$ membrane filters and degassed by ultrasonic vibrationsfor $30 \mathrm{~min}$ prior to use. It was delivered at a flow rate of $0.7 \mathrm{~mL} / \mathrm{min}$ and the injection volume was $5.0 \mu \mathrm{L}$. The column was conditioned for at least 35 min of gradient elution. PDA detection was achieved at $254 \mathrm{~nm}$.

\section{Method Validation}

The proposed method was validated by studying several parameters such as linearity, specificity, accuracy, precision, robustness and system suitability parameters as per the ICH Guidelines

\section{Preparation of Standard Calibration Curve}

The stock solution of EA was diluted to seven different concentrations between 250-750 ppm of working concentration. The calibration graph was plotted by using the concentrations versus average peak area at $254 \mathrm{~nm}$. The linearity of the detector response for the standards was determined by means of linear regression.

\section{Linearity}

The linearity of peak area response for EA was determined from 250-750 ppm of working concentration for EA. The stock solution of Ellagic acid was diluted to seven different known concentrations.

\section{Range}

The range of EA was determined by calculating precision at $50 \%, 100 \%$ and $150 \%$ level of the working standard concentration.

\section{System Suitability Parameters}

The certain resolution and reproducibility of proposed chromatographic system for estimation of EA in Terminalia bellirica extract and capsule formulation, system suitability parameters like retention time, tailing factor and column efficiency (number of theoretical plates, N) were studied. Five replicate solution of standard and test solution in duplicate were injected. The system suitability parameters from standard chromatogram were calculated.

\section{Specificity}

The specificity of the method for Assay was demonstrated by injection of following solutions into the HPLC system.
- Diluent as a Blank

- Standard Solution

- Test Solution

\section{Precision}

Six replicate area of test solution was measured at $254 \mathrm{~nm}$ as per the proposed method. System, method and intermediate precision of the developed method were expressed in terms of relative standard deviation (RSD) of the peak area.

\section{Accuracy}

The accuracy was determined from recovery studies. A known but varying amount of EA was spiked into pre-analysed extract test solution and placebo of formulation at $80 \%, 100 \%$ and $120 \%$ recovery levels of working standard in triplicate. The spiked test solution was analyzed according to the proposed procedure.

\section{Robustness}

To evaluate the robustness of the proposed method, small but deliberate variations in the optimized method parameters were done. The effect of change in flow rate, temperature of column and wavelength ontheoretical plates, tailing factor and \% content were studied. The standard solution containing EA was injected (in triplicate) into the HPLC system under the varied conditions.

\section{RESULT AND DISCUSSION}

In any extract, there are hundreds of unknown components and many of them are in low amount. Moreover, there usually exists variability within the same herbal materials. Consequently, to obtain reliable chromatographic fingerprints that represent pharmacologically active and chemically characteristic components is not an easy or trivial work. Fortunately, HPLC offers very powerful separation ability, such that the complex chemical components in Extract can be separated into many relatively simple sub fractions. Furthermore, the recent approaches of applying hyphenated chromatography and spectrometry such as HPLC PDA detection could provide the additional spectral information, which will be very helpful for the qualitative analysis and even for the on-line structural elucidation. With the help of the spectral information the hyphenated instruments show greatly improved performances in terms of the elimination of instrumental interferences, retention time shift correction, selectivity, chromatographic separation abilities, and measurement precision.

\section{Method development and optimization}

To obtain the best overall chromatographic conditions, differentmobile phase combination were studied for 
Table 1: System suitability parameters of the proposed HPLC method.

\begin{tabular}{|c|c|c|}
\hline Parameters & Ellagic acid & References value \\
\hline Retention time $\left(t_{R}\right)$ & $21.15 \mathrm{~min}$ & - \\
\hline Tailing factor $(T)$ & 1.39 & $\begin{array}{c}\mathrm{T}=1, \text { for a typical } \\
\text { symmetrical peak }\end{array}$ \\
\hline $\begin{array}{c}\text { Number of theoretical } \\
\text { plates }\end{array}$ & 12697 & $\begin{array}{c}\text { Increase with the } \\
\text { efficiency of the } \\
\text { separation }\end{array}$ \\
\hline
\end{tabular}

\begin{tabular}{|c|c|}
$\begin{array}{c}\text { Table 2: Summary of linear regression data of Ellagic } \\
\text { Acid for HPLC. }\end{array}$ \\
\hline Parametrs & Ellagic Acid \\
\hline Linearity range & $250-750 \mathrm{ppm}$ \\
\hline Linear regression equation & $\mathrm{y}=54869.4 \mathrm{x}-3300638.7$ \\
\hline Slope \pm SD & $54869.4 \mathrm{x}$ \\
\hline Intercept \pm SD & 3300638.7 \\
\hline Correlation coefficient $\left(\mathrm{r}^{2}\right)$ & 0.9998 \\
\hline
\end{tabular}

Table 3: Specificity Parameters for HPLC.

\begin{tabular}{|c|c|c|c|}
\hline Standard & Purity Angle & $\begin{array}{c}\text { Purity } \\
\text { Threshold }\end{array}$ & Purity Flag \\
\hline Ellagic Acid & 0.182 & 0.263 & $\begin{array}{c}\text { No Flag } \\
\text { Found }\end{array}$ \\
\hline
\end{tabular}

Table 4: Result of Assay validation parameters for the proposed HPLC method for determination of Ellagic acid in Terminalia bellirica extract and Capsule formulation.

\begin{tabular}{|c|c|c|c|}
\hline \multicolumn{2}{|c|}{ Parameters } & Extract & Formulation \\
\hline \multirow{3}{*}{$\begin{array}{c}\text { Accuracy } \\
(\% \text { mean })\end{array}$} & $80 \%$ & 99.79 & 99.34 \\
\cline { 2 - 4 } & $100 \%$ & 98.17 & 99.75 \\
\cline { 2 - 4 } & $120 \%$ & 98.17 & 99.65 \\
\hline \multirow{2}{*}{$\%$ Assay (w/w \pm SD) } & $0.468 \pm 0.054$ & $0.42 \pm 0.006$ \\
\hline \multicolumn{2}{|c|}{ Precision (\%RSD) } & & \\
\hline \multicolumn{2}{|c|}{ Method Precision } & 1.46 & 1.58 \\
\hline Intermediate Precision & 1.23 & 1.50 \\
\hline
\end{tabular}

\section{Table 5: System Precision parameters for HPLC.}

\begin{tabular}{|c|c|c|}
\hline Name of Analyte & USP Tailing & USP Plate Count \\
\hline Ellagic Acid & 1.77 & 12897 \\
\hline
\end{tabular}

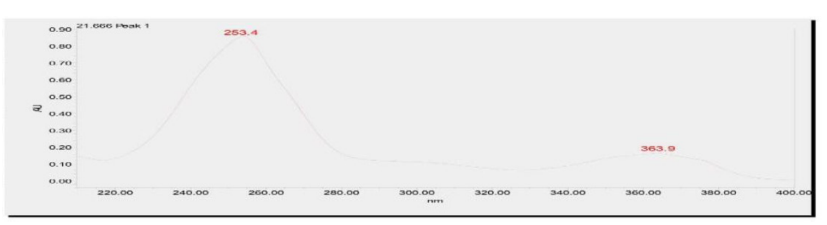

Figure 2: HPLC Spectra for Ellagic Acid.

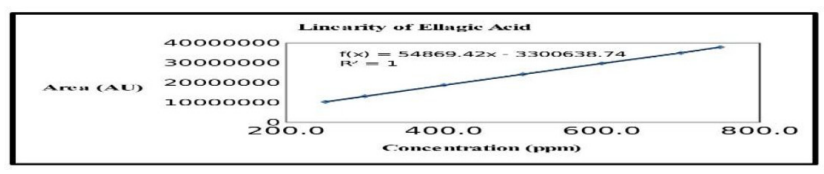

Figure 3: Linearity Graph for Standard Ellagic Acid by HPLC.

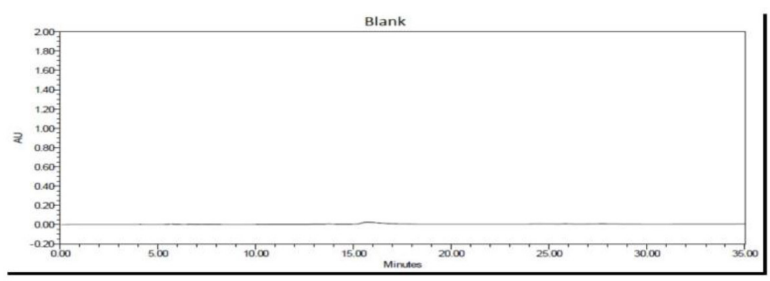

(a)

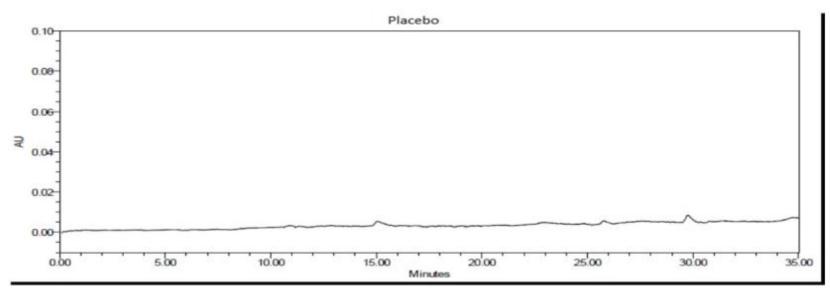

(b)

Figure 4: HPLC chromatogram of Blank solution (a) and Placebo (b).

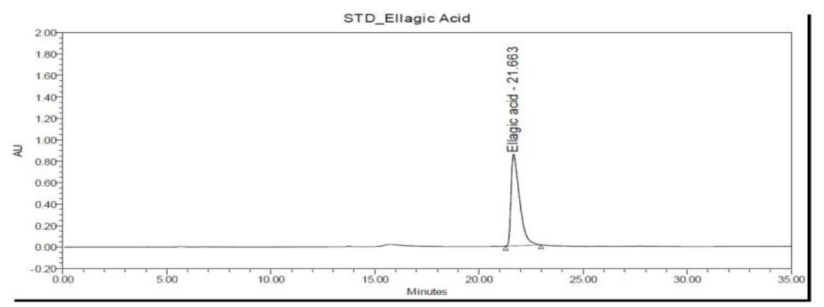

(c)

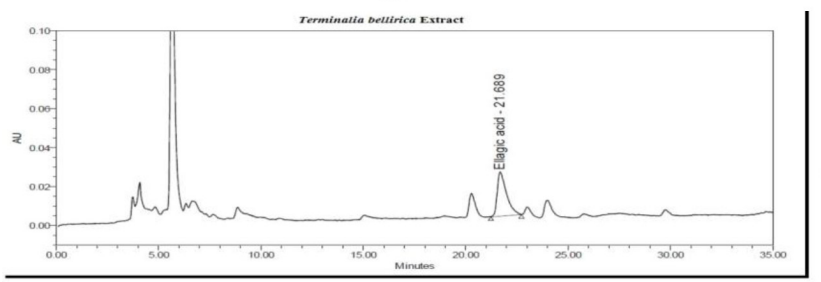

(d)

Figure 4: HPLC chromatogram of Standard Ellagic acid (c) and Determination of Ellagic acid in Extract (d).

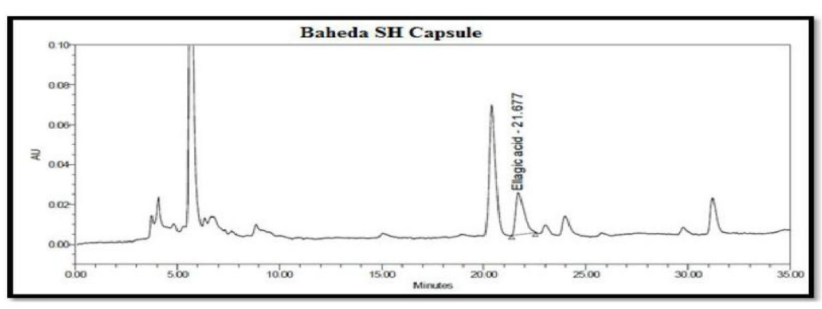

Figure 4: HPLC chromatogram of Determination of Ellagic acid in Formulation (e). 


\begin{tabular}{|c|c|c|c|c|}
\hline Robust parameters & $\%$ RSD & Peak Tailing & Theoretical Plates & Remark \\
\hline \multicolumn{5}{|c|}{ Ellagic Acid } \\
\hline Scanning wavelength: $-5 \mathrm{~nm}$ & 0.40 & 1.77 & 12762 & Pass \\
\hline Scanning wavelength: $+5 \mathrm{~nm}$ & 0.36 & 1.75 & 12704 & Pass \\
\hline Column temperature: $-5^{\circ} \mathrm{C}$ & 0.41 & 1.79 & 14489 & Pass \\
\hline Column temperature: $+5^{\circ} \mathrm{C}$ & 0.17 & 1.80 & 14631 & Pass \\
\hline Flow rate: $-0.1 \%$ & 0.08 & 1.79 & 17129 & Pass \\
\hline Flow rate: $+0.1 \%$ & 0.12 & 1.80 & 16135 & Pass \\
\hline
\end{tabular}

separation of Ellagic acid from Terminalia bellirica extract. The composition of solvent system for HPLC analysis was optimized by testing different solvent systems of varying polarity and the best results were obtained n-hexane sulfonic acid and Methanol (70:30) as Gradient elution. The mobile phase was optimized by examining the effect of $\mathrm{pH}$ and content of Methanol. Other chromatographic variables were investigated including column type and flow rate. The retention time for EA is found to be $21 \mathrm{~min}$.

\section{METHOD VALIDATION}

\section{Linearity and Range}

Peak areas were found to have good linear relationship with the concentration as shown in Figure 3. The linearity graph shown coefficient of correlation $\left(\mathrm{R}^{2}\right)$ was found to be 0.9998 for EA. Calibration graphs were constructed in the ranges of $250-750 \mathrm{ppm}$ for EA. The correlation coefficients, $y$-intercepts and slopes of the regression lines of the compounds were calculated and presented in Table 2.

\section{Precision}

The results showed that the system, method and intermediate variation of the results for estimation of $\mathrm{EA}$ was within the acceptable range. The sample was also analyzed by two different analysts within the same day and the results revealed that there is good intermediate precision. The area was measured and the \% RSD found to be less than 2 are observed for extract and formulation respectively which is within acceptable limit indicates the precision of the system was shown in Table 4 and Table 5.

\section{Quantification of Ellagic acid in the extract and in single herbal formulation containing Terminalia bellirica}

$5 \mu \mathrm{L}$ of the extract and $10 \mu \mathrm{L}$ of formulation were injected to in sixlet and the amount of EA in samples were determined by using Method precision. The results were shown in \% Assay in Table 2. This method shows the presence of $0.468 \pm 0.054 \% \mathrm{w} / \mathrm{w}$ in extract, $0.42 \% \pm 0.006 \mathrm{w} / \mathrm{w}$ in formulation respectively.

\section{Accuracy}

Accuracy was also assessed by standard addition technique and the percentage recoveries were calculated and found to be in the range of $98 \%$ to $99 \%$ for extract and formulation against respective levels as mentioned in Table 4 respectively. The results showed that the suggested method is reliable and reproducible.

\section{Specificity}

Specificity of the methods was tested by how accurately and specifically the analytes of interest are determined in presenceof other components. Peak purity testing was done to ensure purity of the peaks in HPLC method. This is evident from HPLC chromatogram shown in Figure 4 proved the specificity of the proposed method and the results obtained confirmed the purityof EA peak shown in Table 3.

\section{Robustness}

Robustness of an analytical procedure is the capacity of themethod to remain unaffected with small deliberate variations in method parameters and provides an indication of its reliabilityduring normal usagee.g.: flow rate $\pm 0.1 \mathrm{ml} / \mathrm{minin}$ HPLC method and changing the scanning wavelength $\pm 5 \mathrm{~nm}$ and column temperature $\pm 5^{\circ} \mathrm{C}$ for the proposed methods. Robustness data is shown in Table 6. The value of \% RSD which is less than 2 shows that the methods are robust and that the deliberate small change in the studied factors did not lead to significant changesin retention time values, area or symmetry of the peaks.

\section{System suitability}

An overall system suitability testing was done to determine if the operating system were performed properly. Parameters including retention time, tailing factor and number of theoretical plates were calculated where good results were obtained and peak information is 
given in Table 1. Typical chromatogram obtained is shown in Figure 2.

\section{CONCLUSION}

A simple and efficient reverse-phase HPLC method was developedfor the identification and quantification of EA in fruit extracts of T. bellirica and capsule formulation. The developed HPLCmethod is simple, precise, time saving, economic and accurate. Further, it was also validated as per ICH guidelines. The developed HPLC method analysis is rapid, therefore, suitable for quantitative analysis as well as quality control of extracts and herbal formulations from Terminalia bellirica species.

\section{ACKNOWLEDGEMENT}

The authors are grateful to the $\mathrm{R}$ and $\mathrm{D}$ Center of Ari Healthcare Pvt. Ltd,Unit No. 401, International Biotech Park, BTS-2 Building, Chrysalis Enclave, 4th Floor, Plot No - 2A, MIDC Phase II, Hinjewadi, Pune - 411057, Maharashtra, India for providing necessary facilities to carry outthis work.

\section{CONFLICT OF INTEREST}

There are no conflicts of interest.

\section{ABBREVIATIONS}

HPLC-PDA: High performance liquid chromatographyPhotodiode array detector; EA: Ellagic acid; ICH: International Council of Harmonisation.

\section{REFERENCES}

1. Dwivedi S, Chaturvedi A. Cardiology in ancient India; Journal of Indian College of Cardiology. 2000;1:8-15.

2. S. Shatvalekar, Atharvavedasamhita, VasantShripadShatvalekar, Swadhyaya Mandal. Pardi, Balsad, Maharashtra. India. 1943;1:25.

3. Singh DV, Verma RK, Singh SC, Gupta MM. RP-LC determination of oleane derivatives in Terminalia arjuna. Journal of Pharmaceutical and Biomedical Analysis. 2002;28(3-4):447-52.

4. Kirtikar KR. Indian medicinal plants; Oriental Enterprises, Uttaranchal, India. 2001;2(5):1415-39.

5. Chen LG, Huang WT, Lee LT, Wang CC. Wang, Ellagitannins from Terminalia calamansanai induced apoptosis in HL-60 cells; Toxicology in vitro. 2009;23(4):603-9.

6. Chadha YR. The Wealth of India, raw materials. CSIR, New Delhi, India. 1998;10:157-8.

7. Row JR, Murty PS. Chemical examination of Terminalia bellirica Roxb; Indian Journal of Chemistry. 1970;8:1047-8.

8. Thakur RS, Puri HS, Husain A. Husain, Major medicinal plants of India; Central Institute of Medicinal and Aromatic Plants, Lucknow, India. 1989;493-4.

9. Tariq M, Hussain SJ, Asif M, Jahan M. Jahan, Protective effect of fruit extracts of Emblicaofficinalis (Gaertn.) and Terminalia bellirica Roxb. in experimental myocardial necrosis in rats; Indian Journal of Experimental Biology. 1977;15(6):485-6.
10. Fan YM, Xu LZ, Gao J, Wang Y, Tang XH, Zhao XN. Phytochemical and antiinflammatory studies on Terminalia catappa; Fitoterapia. 2004;75(3-4):25360.

11. Bala I, Bhardwaj V, Hariharan S, Kumar MR. Analytical methods for assay of Ellagic acid and its solubility studies, Journal of Pharmaceutical and Biomedical Analysis. 2006;40(1):206-10.

12. Xiang L, Xing D. Effects of Season, Variety, and Processing Method on Ellagic Acid Content in Pomegranate Leaves, Tsinghua Science and Technology. 2008;13(4):460-5.

13. Sharma G, Italia L, Sonaje K. Biodegradable in situ Gelling System for Subcutaneous Administration of Ellagic Acid and Ellagic Acid Loaded Nanoparticles: Evaluation of Their Antioxidant Potential against Cyclosporine Induced Nephrotoxicity in Rats, Journal of Controlled Release. 2007;118(1):27-37.

14. M S Bagul, M. Rajani. Physicochemical evaluation of classical formulation A case study. Indian Drugs. 2005;42:15-9.

15. Jagetia GC, Baliga MS, Malagi KJ, Kamath MS, The evaluation of the radioprotective effect of Triphala (an Ayurvedic rejuvenating drug) in the mice exposed to radiation. Phytomedicine. 2002;9(2):99-108.

16. $\mathrm{ICH}$ Q1A (R2). Harmonized tripartite guideline, validation of analytical procedure methodology, IFPMA, proceedings of the international conference on harmonization, Geneva, (2003).

17. Lin TC, Chien SC, Chen HF, Hsu FL. Hsu, Tannins and related compounds from Combretaceae plants; The Chinese Pharmaceutical Journal. 2000;52(1):1-26.

18. Juang LJ, Sheu SJ, Lin TC. Determination of hydrolysable tannins in the fruit of Terminalia chebula Retz. By high performance liquid chromatography and capillary electrophoresis; Journal of Separation Science. 2004;27(9):718-24.

19. Singh DP, Govindarajan R, Rawat AK. S Rawat, High-performance liquid chromatography as a tool for the chemical standardization of Triphala-an ayurvedic formulation; Phytochemical Analysis. 2008;19(2):164-8.

20. Pawar V, Lahorkar P, Narayana DA. Development of a RP-HPLC method for analysis of Triphala Churna and its applicability to test variations in Triphala Churna preparations; Indian Journal of Pharmaceutical Sciences. 2009;71(4):382-6.

21. Dalluge JJ, Nelson BC, Thomas JB, Sander LC. Selection of column and gradient elution system for the separation of catechins in green tea using high-performance liquid chromatography; Journal of Chromatography. 1998;793(2):265-74.

22. Mahajan AD, Pai NR. Development and validation of HPLC method for quantification of phytoconstituents in Haritaki Churna; International Journal of Chem Tech Research. 2011;3(1): 329-36.

23. Hsu HC, Chien CS. Validation of analytical methods: a simple model for HPLC assay methods; Journal of Food and Drug Analysis. 1994;2(3):161-76.

24. Chen GL. Stability indicating high performance liquid chromatographic assay methods for drugs in pharmaceutical dosage forms: part I; Journal of Food and Drug Analysis. 1996;4(4):271-92.

25. Chen GL. Stability indicating high performance liquid chromatographic assay methods for drugs in pharmaceutical dosage forms: part II; Journal of Food and Drug Analysis. 1997;5(1):1-24.

26. Rajagopalan T, Khambe D. United States Patent-5843987 Method of Stimulating Gastrointestinal Motility with Ellagic acid. 1998; 1-8.

27. Singh DP, Govindarajan R, Rawat AK. Rawat, High-performance Liquid Chromatography as a Tool for the Chemical Standardization of Triphala an Ayurvedic Formulation, Phytochem. Anal. 2008;19(2):164-8.

28. $\mathrm{ICH}(\mathrm{Q} 2)$ (R1). Harmonized tripartite guideline, validation of analytical procedure methodology, IFPMA, proceedings of the international conference on harmonization, Geneva, (2005).

29. Anonymous. The Ayurvedic Formulary of India. Part-II, Govt. of India, Ministry of Health and Family Welfare, Dept. of Indian Systems of Medicine and Homeopathy, New Delhi. 110.

30. Anonymous, the Indian Pharmacopoeia, Part-II, Appendix-3, Govt. of India, Ministry of Health and Family Welfare. A-34. 1996;2:350.

31. Anonymous, Quality Standards of Indian Medicinal Plants, Published by Indian Council of Medicinal Research. 2003;1.

32. International Conference on Harmonization, Guideline on Validation of Analytical Procedure-Methodology, Geneva, Switzerland. 1996.

33. International Conference on Harmonization (ICH); Q2 9(R1): technical requirements for registration of pharmaceuticals for human Use; validation 


\section{PICTORIAL ABSTRACT}

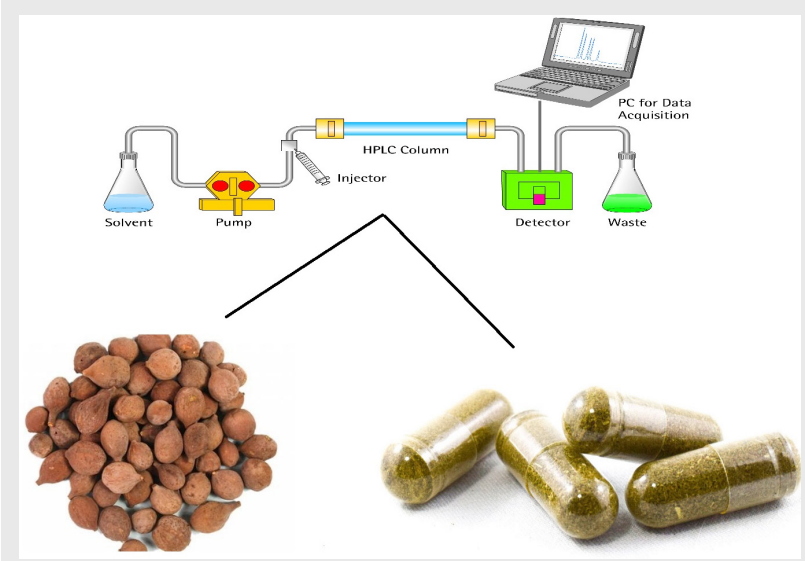

\section{About Authors}

Dr. Dheeraj Hanumansingh Nagore, Senior Manager, Analytical Department, Ari Healthcare Private Limited, $\mathrm{R}$ and D Centre, Unit No. 401, International Biotech Park, BTS-2 Building, Chrysalis Enclave, $4^{\text {th }}$ Floor, Plot No - 2A, MIDC Phase II, Hinjewadi, Pune - 411057, Maharashtra, INDIA.

\section{SUMMARY}

- The present work describes development of a simple, specific, sensitive, precise and robust high performance liquid chromatographic method of analysis of Ellagic acid, as in Terminalia bellirica extract and from capsule formulation. A validated rapid HPLC-PDA method was developed for identification and quantification of Ellagic acid (EA) in the extracts prepared from the fruits of Terminalia bellirica available in India. The separation was achieved by using mobile phase in composition of $\mathrm{n}$-Hexane sulfonic acid (20 mM) and 100\% Methanol (Gradient programme) at flow rate of $0.7 \mathrm{ml} /$ min was used. The results of formulation analysis were validated as per International Council of Harmonization $(\mathrm{ICH})$ guidelines indicating high degree of accuracy. The \% R.S.D. value which is less than to 2 for robustness study suggests that the developed HPLC methods are unaffected by small changes in process parameters.

Cite this article: Ganjage PJ, Tapkir AS, Nipanikar SU, Nagore DH, Pawar PK, Phophase ML. Development and Validation of a RP-HPLC Method for the Determination of Ellagic Acid in Terminalia bellirica Extract and Single Herb Capsule of Terminalia bellirica. Indian J of Pharmaceutical Education and Research. 2018;52(4S):S56-S62. 